\title{
ACCOUNTABILITY: \\ Novo conceito para a Ciência da Informação?
}

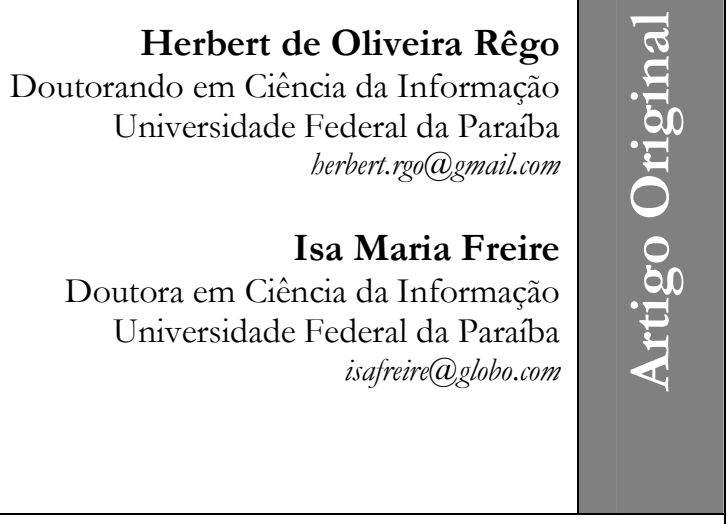

\section{Resumo}

Discorre sobre as mudanças ocorridas na gestão pública no Brasil, nas últimas décadas, oriundas de transformações impostas pela Constituição de 1988 e pelo crescimento de um movimento de cidadanização, no contexto da disseminação das tecnologias digitais de comunicação e informação. Ressalta que há uma lacuna dessa discussão na literatura da Ciência da Informação e discute o contexto da accountability e da transparência no Brasil, e as políticas de informação na sociedade em rede. Destaca a necessidade de uma concepção do que seja accountability para a Ciência da Informação, de modo que os profissionais da área assumam o protagonismo no movimento da cidadania para a transparência, na implantação dos portais de transparência, no contexto da interatividade comunicativa e da ação responsável no campo da informação.

\section{Palavras-chave}

Políticas públicas. Accountability. Ciência da Informação. Políticas de informação. Cidadania. Lei de Acesso à Informação. Brasil.

\section{INTRODUÇÃO}

A presente comunicação compartilha reflexões sobre a abordagem do projeto $O s$ portais de transparência à luz da Ciência da Informação: um modelo de interface para acesso à informação, do Departamento de Finanças e Contabilidade em parceria com o Departamento de Ciência da Informação, da Universidade Federal da Paraíba (UFPB), que integra a rede de projetos do Laboratório de Tecnologias Intelectuais - LTi . com apoio do Conselho Nacional de Desenvolvimento Científico e Tecnológico (CNPq) ${ }^{1}$.

Os Portais de Transparência são uma interface de comunicação entre a sociedade e

$1 \mathrm{O}$ presente texto incorpora as reflexões derivadas do diálogo com os pesquisadores a partir da comunicação oral apresentada no GT5 - Política e Economia da Informação do XVIII ENANCIB.. o governo, de modo a facilitar o acesso à informação pública. Nesses Portais, deve ser possível ao cidadão realizar pesquisas e acessar informações sobre as ações do governo em qualquer nível. Nesse contexto, o projeto tem como objetivo proceder à análise dos portais de transparência das capitais brasileiras, à luz de indicadores sociais, econômicos e políticos, como também da Ciência da Informação, especialmente as áreas de políticas e gestão da informação e organização do conhecimento para recuperação da informação.

Ao acompanharmos a evolução das mudanças ocorridas no Brasil nas últimas décadas, como visto em Freire e Rego (2016a, 2016b), observamos que há um movimento emergente, principalmente na gestão pública, oriundo das transformações impostas pela Constituição de 1988 e pela 
disseminação das mídias digitais. Trata-se da accountability, um tema ainda pouco difundido e, mesmo, definido, mas de grande interesse para o processo de cidadanização ${ }^{2}$ da população brasileira. Este tema já é discutido na Ciência Política e também nas Finanças Públicas, porém há uma lacuna dessa discussão na literatura da Ciência da Informação. ${ }^{3}$ Nosso propósito, com o presente relato de pesquisa, é contribuir para a discussão sobre o direito à informação, que está na essência do movimento pela cidadania.

\section{CULTURA DE ACCOUNTABILITY NO BRASIL}

Certamente, quando tratamos de accountability estamos tratando de democracia e cidadania. Nesse sentido, iniciamos explorando os fundamentos da democracia que, segundo Abrucio e Loureiro (2004), se apoiam em três princípios:

a) o governo deve ser derivado da vontade popular;

b) os governos devem ter responsabilidade pelos seus atos no exercício do poder perante o povo; e

c) o Estado deve ser balizado por leis que delimitem sua ação em favor dos direitos básicos individuais e coletivos dos cidadãos.

São estes fundamentos da democracia que no Século 21 destinam-se a garantir a accountability, o agir com responsabilidade no trato da coisa pública. Este conceito ainda está sendo construído e há um forte debate sobre o tema, como mostram Pinho e Sacramento (2009), bem como Oliveira, Carvalho e Corrêa (2013). Essa responsabilidade de uma instituição pública perante um indivíduo ou organização fora de si mesma contém a essência da governança e ainda se en-

\footnotetext{
2 A expressão "cidadanização" foi originalmente trabalhada por Duarte et al. (1993). Trata-se da incorporação social e política que se apoia sobre o triplo processo de individualização, racionalização e responsabilização.

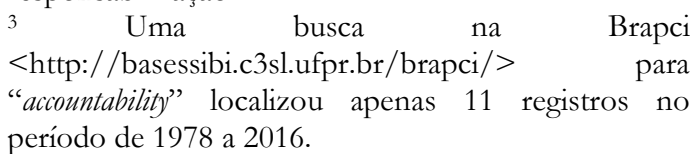

contra embrionária na gestão pública brasileira.

Um dos autores seminais nessa temática é O’Donnell $(1998)^{4}$, cujo modelo de abordagem destaca duas dimensões a responsabilização democrática:

a) vertical, estabelecida entre agentes não estatais e estatais, no pressuposto de que os cidadãos controlam os governos através das eleições e da garantia da soberania popular e do controle social Para o autor, este elemento democrático já se fazia presente e consolidado em muitas poliarquias; e

b) horizontal, que se efetiva através da fiscalização mútua entre os três poderes e "é produto de uma rede de agências que tem seu cume nos tribunais comprometidos com a accountability"

LOUREIRO, 2004, p.82).

Entre agentes estatais, para a ação de accountability horizontal acontecer faz-se necessário o uso de instrumentos de publicidade das informações governamentais, de modo a colocar seus atos sob o controle social mediante transparência pública, e do controle administrativo, através dos tribunais de contas e do controle judicial.

No Brasil a discussão a respeito da accountability surgiu com vigor a partir de artigo de Campos, em 1990. O contexto histórico da elaboração do artigo foi o final dos anos 1980, início da redemocratização e promulgação da Constituição Federal brasileira.

Inicialmente deve-se reconhecer a necessidade de disponibilidade, por parte da burocracia oficial, de mecanismos de controle que não sejam aqueles exercidos por órgãos internos do governo: não é possível imaginar uma pessoa realizando accountability de si mesma. $O$ verdadeiro controle vem da responsabilidade objetiva, da pessoa perante outra pessoa, e é exercido

\footnotetext{
4 Seus conceitos sofrem duras críticas, como, por exemplo, de Schedler (1999) e Mainwaring (2003), porém O`Donnell (1998) é o ponto de partida do debate teórico.
} 
pelos cidadãos, pois somente eles detêm a legitimidade para controlar o governo, seja ele executivo, legislativo ou judiciário. Percebe-se, por suposto, que o ambiente democrático é fundamental, e mesmo condição sine qua non, para que haja controle do governo pelos cidadãos. Sobre o tema, Campos (1990, p.33, grifo do autor) diz explicitamente, no seu texto seminal:

Quanto mais avançado o estágio democrático, maior o interesse pela accountability. E a accountability governamental tende a acompanhar o avanço de valores democráticos, tais como igualdade, dignidade humana, participação, representatividade. [...]. Não haverá tal condição enquanto o povo se definir como tutelado e o Estado como tutor.

$\mathrm{Na}$ época da publicação do artigo de Campos (1990) eram muitas as fragilidades da democracia brasileira, no período histórico denominado de Nova República, e o autor cita algumas: tais como a desigualdade, vista como uma fatalidade; a fraca representatividade partidária nas eleições; os governos populistas; a ausência de associações comunitárias que não fossem iniciativas oficiais; a visão do cidadão apenas como um contribuinte e eleitor. Tais elementos da sociedade brasileira, conforme Campos (1990), demonstram o longo percurso que precisávamos caminhar como sociedade para alcançarmos $\mathrm{O}$ desenvolvimento econômico e político. $\mathrm{O}$ autor encerra o artigo respondendo à pergunta que usa como título: "Accountability: quando poderemos traduzi-la para $\mathrm{O}$ português?". E nos diz que, "por enquanto, qualquer tentativa apressada de cunhar uma palavra seria desprovida de significado, pois não faria parte da nossa realidade" (CAMPOS, 1990, p.48). O tempo para traduzir a palavra ainda não chegara.

Duas décadas depois, Pinho e Sacramento (2009) retomam o artigo de Campos (1990), e com isso disponibilizam material para se fazer um paralelo entre os dois momentos da realidade brasileira, no passado distante e no passado próximo. $\mathrm{O}$ principal fato ocorrido no intervalo de tempo entre os dois artigos foi o surgimento dos primeiros efeitos das mudanças ocorridas como consequência da promulgação da Constituição Federal de 1988 (Constituição Cidadã), pois a partir dela se institucionalizou a participação popular na governança pública. Criaram-se conselhos e orçamento participativo, tornando possível ao cidadão acompanhar de forma ativa as decisões do governo, desenvolvendo a ação popular, que dá ao cidadão a possibilidade de defender $\mathrm{o}$ interesse coletivo. Outro marco legal, fundamental para a accountability no Brasil, foi o estabelecimento do direito à informação, sem o qual provavelmente não estaríamos no estágio avançado de transparência das instituições públicas brasileiras que temos hoje. Houve, também, a descentralização do governo federal, quando se estabeleceu a transferência de responsabilidades e competências para os governos federativos, abrindo espaço para a viabilização da transparência dos governos locais, uma vez que é mais fácil para o cidadão fiscalizar o Prefeito do que o Presidente da República. Nesse contexto, a Lei de Responsabilidade Fiscal (2000) e a criação da Controladoria Geral da União (2001) foram responsáveis por avanços significativos para a gestão pública.

Assim como fez Campos (1990) ao final do seu artigo, Pinho e Sacramento também responderam à pergunta, "accountability: já podemos traduzi-la para o português?”. A resposta dos autores, em 2009, assinala que o Brasil já está mais perto da tradução do que no período em que Campos se defrontou com a questão. Em 20 anos mudanças ocorreram na legislação, como também na cultura dos brasileiros, porém o caminho é longo para se observar uma cultura de accountability incorporada ao ethos do povo brasileiro.

\subsection{Cultura da transparência no Brasil}

A cultura da transparência surge como resultado das lutas históricas por 
maiores liberdades individuais e com isso o estabelecimento dos direitos humanos. Foi a partir da Declaração Universal dos Direitos Humanos (1948), que a Organização das Nações Unidas (ONU) sugeriu a criação de leis específicas para a implementação do movimento da transparência na sociedade brasileira. Nesse contexto, o Brasil foi $90^{\circ}$ país a aderir a este movimento, no contexto mundial (FONSECA E SÁ; MALIN, 2012). Recentemente, a ONU (2015) atualizou sua política sobre direitos humanos, incluindo o ambiente virtual através da Carta de Direitos e Princípios da Internet, que tem como um dos seus objetivos "aumentar a conscientização sobre a carta à luz da crescente preocupação pública nacional e internacional sobre a proteção e o gozo dos direitos humanos online, bem como offline". Nesse sentido, no Brasil, segundo Freire; Rego; Oliveira (2015, p.179), a Constituição Federal (1988):

[...] em seu artigo $5^{\circ}$, no inciso XXXIII prevê que "todos tem direito a receber dos órgãos públicos informações de seu interesse particular, ou de interesse coletivo ou geral", considerando este direito como relativo a direitos e garantias fundamentais individuais e coletivas. Ainda na Constituição Federal o artigo $216^{\circ}$, parágrafo $2^{\circ}$ prevê que "Cabem à administração pública, na forma da lei, a gestão da documentação governamental e as providências para franquear sua consulta a quantos dela necessitem".

Apesar da constitucionalidade deste direito, sua efetivação só ocorreu após 23 anos da promulgação da Constituição, em 2011, quando ocorreu sua regulamentação através do Decreto-Lei Federal $\mathrm{n}^{\circ}$ 7.724/2012. Esta Lei entrou em vigor em 16 de maio de 2012 e desde então tem sido objeto de regulamentação em outros poderes da União, bem como nos Estados e Municípios (JARDIM, 2012, p. 3). A partir dessa Lei de Acesso à Informação (LAI), ficaram estabelecidas as garantias do direito de acesso à informação, os procedimentos aos pedidos de acesso, as restrições, as responsabilidades dos agentes públicos, entre outros, promovendo, então, um ponto de inflexão na gestão pública brasileira. Meijer (2009) apresenta um modelo de abordagem da evolução das características da transparência a partir das seguintes categorias:

a) pré-moderna, que se caracteriza pela falta de uma mediação, sendo realizada na forma face-a-face, como, por exemplo, nas reuniões tradicionais;

b) moderna, na qual a mediação é fundamental, visto o desenvolvimento das mídias digitais (transparência mediada); neste caso seria unilateral, não havendo interação entre as partes; e por último,

c) pós-moderna, que se caracteriza pela interação entre as partes, através das mídias digitais.

Nesse contexto, um portal virtual de transparência representa uma revolução na relação entre a sociedade e o governo, por sua função de facilitar o acesso à informação pública, de modo que o cidadão pode realizar pesquisas e acessar informações sobre as ações do governo em qualquer nível, mediante o uso da Internet. Pois, apesar de ainda existirem pessoas que não têm acesso ao espaço virtual, ou ciberespaço ${ }^{5}$, vivemos na sociedade em rede, onde a maioria da população dispõe de oportunidades para conexão por meio de plataformas digitais móveis.

De modo que quando falamos de transparência falamos de uma revolução onde a forma de manutenção do poder político, antes baseada no esvaziamento do espaço público e suas derivações, está se transformando, caminhando para a construção de uma nova forma de espaço público, mais

\footnotetext{
5 Para Lévy (1999, p.17), "O termo [ciberespaço] especifica não apenas a infraestrutura material da comunicação digital, mas também o universo oceânico de informação que ela abriga, assim como os seres humanos que navegam e alimentam esse universo".
} 
dinâmico e democrático. ${ }^{6}$ Nesse espaço, o cidadão tende a deslocar-se da periferia do sistema do poder para sua centralidade, e isso será possível através do processo de comunicação estabelecido pela sociedade em rede $^{7}$. Como demostrou Keer Pinheiro (2012), as tecnologias da informação permitiram o desenvolvimento de repositórios coexistindo sem princípios diretores, e ao longo do tempo espera-se ser possível estabelecer o Estado informacional, de modo a promover uma sinergia entre os inúmeros repositórios distribuídos entre os vários centros de informação.

Esperamos ter demonstrado a demanda por abordagens da temática "transparência" no campo da Ciência da Informação, considerando-se a intenção ou propósito da informação, qual seja alterar o campo de consciência dos sujeitos numa relação comunicativa. ${ }^{8}$ Quando há a interatividade entre os agentes públicos e os cidadãos, criase a oportunidade para uma transformação social e cultural, só possível pelas inovações das tecnologias digitais de informação e comunicação, que, segundo Assmann (2000, p.9), "ampliam o potencial cognitivo do ser humano (seu cérebro/mente) e possibilitam mixagens cognitivas complexas e cooperativas".

De modo que a participação da Ciência da Informação tanto no estudo quanto na implementação da cultura da accountability torna-se, por definição, fundamental para o processo brasileiro de cidadanização. Seria inconcebível manter a discussão sobre transparência apenas nos limites das Finanças Públicas e da Ciência Política, pois o tema tem uma complexidade ímpar que necessita de uma abordagem teórica multidisciplinar. E no contexto da Ciência da Informação, nos perguntamos como podemos contribuir para uma nova cultura política fundamentada na

\footnotetext{
${ }^{6}$ Conforme Lévy (2000), na sua utopia de uma ágora mundial, facilitada pelas mídias virtuais conectadas à Internet. Ver também Freire, 2005.

${ }^{7}$ Há autores que trabalham com uma visão diferente, como Keen (2009).

${ }^{8}$ Conforme Barreto (1994).
}

transparência. Questão que abordaremos, no escopo da nossa pesquisa, a seguir.

\section{A RESPONSABILIDADE SOCIAL DA CIÊNCIA DA INFORMAÇÃO}

Como visto, a informação vem sendo reconhecida como um instrumento de transformação social, a ponto de qualificar a sociedade contemporânea como "sociedade da informação", e as transformações tecnológicas continuam a influenciar indivíduos e grupos sociais através da disseminação da informação. A internet, rede mundial de computadores, a partir da tecnologia word wide web (www) e da chamada web semântica (web2), impulsionaram ainda mais a disseminação da informação.

Diante desta realidade, onde a questão da organização e guarda das informações científicas não é mais uma ação suficiente na contemporaneidade, que agora oferece um novo desafio aos profissionais da informação, qual seja, o de promover seu compartilhamento em ampla escala. Neste raciocínio Freire e Araújo (1999), enfatizam o desafio aos profissionais da informação, que estaria em prover o acesso à informação, o novo fator de produção social, através dos mais diversos canais aos seus consumidores finais, a nosso ver aos cidadãos. Nesse sentido, Freire (2001, p.154) ressalta a complexidade da responsabilidade social da Ciência da Informação, considerando que

[...] o seu objeto de estudo pertence ao universo dos fenômenos da comunicação social, em particular a comunicação entre um emissor e um receptor de mensagens com o objetivo de promover mudanças em suas respectivas estruturas de percepção e conhecimento.

Conforme Zins (2007) citado por Santos e Cardoso Filho (2011), a Ciência da Informação tem no seu campo de estudo abordagens sobre mediação, e esse processo apresenta aspectos cognitivos, tecnológicos e sociais que contribuem para o conhecimento, por isso, e a nosso ver, a relevância de estudos sobre portais de transparência. Con- 
forme identificado por Freire (2015), a preocupação com o tema da responsabilidade social surge na literatura da Ciência da Informação indexada pela Base de Dados Referenciais em Ciência da Informação (Brapci) ${ }^{9}$ no final do Século 20, e só começa se tornar mais presente a partir de 2004, o que vem sinalizar o interesse dos pesquisadores da Ciência da Informação sobre o tema.

Como em outras ciências sociais, a Ciência da Informação vai respondendo proativamente às novas condições históricas e tecnológicas, e no caso brasileiro a realidade torna essa tarefa mais desafiadora devido à grande desigualdade econômica e social na população. É nessa ambiência que o movimento de accountability está surgindo com força e velocidade, na sociedade brasileira.

Socializar a informação em um ambiente com maior controle legal, acessível para cidadãos mais críticos e demandantes de uma interatividade, só é possível em um ambiente democrático turbinado pela revolução das mídias digitais, embora na ambiência de um Estado ainda ineficiente face às demandas existentes e pouco capacitado para disponibilizar informações consideradas estratégicas. Certamente esse contexto vem a exigir mais habilidades dos profissionais da informação, levando-se em conta que os portais de transparência são dinâmicos e podem ser oferecidos em diversos formatos.

\subsection{Accountability no contexto das políticas de informação}

Como resultado da nossa incursão do território da literatura sobre accountability no campo da Ciência da Informação, dialogamos, a seguir, com abordagens que nos parecem aproximadas da rede conceitual da nossa pesquisa sobre portais de transparência.

Iniciamos com Jardim (2008, p. 6), que nos apresenta a noção de políticas públicas de informação como

\footnotetext{
${ }^{9}$ Disponível em:

http://www.brapci.ufpr.br/brapci/.
}

[...] conjuntos de premissas, decisões e ações - produzidas pelo estado $\mathrm{e}$ inseridas nas agendas governamentais em nome do interesse social - que contemplam os diversos aspectos (administrativo, legal, científico, cultural, tecnológico, etc.) relativos à produção, uso e preservação da informação arquivística de natureza pública e privada.

Tal pressuposto nos permite transitar pelos "vários aspectos" de políticas públicas, desde seus dispositivos legais, quanto seus aspectos culturais e tecnológicos, entre outros. Um conceito também relevante para nossa abordagem foi apresentado por Braman (2011, p.3, tradução nossa), corroborando no que diz respeito ao papel fundamental do Estado na implementação das políticas de informação:

\section{Política de informação é composta por leis, regulamentos e posições doutrinárias - e outras tomadas de decisão e práticas com efeitos constitutivos sobre toda a sociedade - que envolvem geração, processamento, fluxo, acesso e uso da informação.}

Esta participação do Estado se deve à relevância da política de informação nas agendas dos Estados nacionais, já que são empregados como instrumentos de poder, o qual, nos últimos anos, no caso do Brasil, vem sendo gradativamente compartilhado com outros atores, as organizações sociais e os cidadãos. Tais mudanças foram possíveis por intermédio das tecnologias digitais de informação, sendo este um parâmetro e um propulsor de mudanças com disposição para reformular os outros meios. Para Braman (1995 apud González de Gómez, 2015, p.327), "é preciso redefinir o corpo híbrido de atores, práticas e meios, pautado pela transversalidade, convergência e nomadismo da tecnologia digital", para que novas políticas de informação tenham onde se firmar.

É neste contexto que ocorre a interação entre os diferentes atores do 
regime de informação da sociedade em rede, com o objetivo de aumentar seus respectivos controle e domínio. Braman (2004) denomina o regime de informação atual como "regime global emergente de informação", global porque contém os atores estatais e não estatais, e emergente porque está em formação, por definição. Para González de Gómez (2012, p.52), este conceito traz vantagens para a abordagem das políticas de informação,

[por] sua plasticidade e [seu] distanciamento das categorizações das políticas de informação já estabelecidas, o que permite a reflexão e a análise do caráter transversal da informação e das tecnologias de informação [e de comunicação], sua capilaridade e facilidade de imersão em todas as dimensões e tipos de atividade social.

Nesse contexto, é relevante observar que uma política, seja de informação ou de outras categorias de problemas, não é apenas a soma de programas ou sistemas, havendo necessidade da definição geográfica, informacional, econômica, e, além disso, da especificação dos atores que estarão no processo de implementação e avaliação dessas políticas. Para Pinheiro (2012, p.67), uma política de informação seria "Aquela que engloba leis e regulamentos que lidam com qualquer estágio da cadeia de produção da informação, desde a sua criação, processamento (natural ou artificial), armazenamento, transporte, distribuição, busca, uso e a sua destruição".

A importância do tema das políticas de informação no espaço público é reforçada pela preocupação dos organismos internacionais em colocá-lo em suas pautas de orientações, como a Organização das Nações Unidas para a Educação, a Ciência e a Cultura (UNESCO, 2007, p. 89, tradução nossa), quando estabelece uma definição de política Nacional de Informação como:

a) política de Estado capaz de gerar ações que reduz o hiato existente no acesso, uso e exploração da informação, tanto aquela do domínio público como a do domínio privado, com um quadro de equidade, segurança e justiça, para promover o conhecimento.

b) [...] que estabeleça mecanismos e gere ações voltadas para garantir o acesso, a utilização, a exploração e a preservação da informação, tanto aquela do domínio público como a do domínio privado, por toda a população, em um quadro de equidade, desenvolvimento sustentável e justiça social.

c) [e apresente] Cursos de ação planejada, definida pelos tomadores de decisão públicos como política de Estado com a participação de todas as partes interessadas, especialmente da sociedade civil e do setor privado para garantir o acesso, a utilização e a exploração da informação de domínio público e privado, através de diversos meios e formatos dos cidadãos em condições de igualdade.

Um dos objetivos de uma política de informação dirigida à transparência, no sentido da accountability, seria a eliminação, o quanto for possível, da assimetria de informação entre o governo e os cidadãos. Esta assimetria, representada principalmente pelo processo burocrático nas agências governamentais, dificulta a um indivíduo exercer seu direito à informação como cidadão, e aí se encontra um desafio para a Ciência da Informação, que poderá contribuir de forma efetiva para a sua concretização. Os pesquisadores Marques e Kerr Pinheiro (2011, p.73) conceituam assimetria informacional como:

[...] a distribuição da informação entre atores sociais por meio de processos não uniformes, irregulares, desproporcionais ou sem equilíbrio de forças, no contexto de relações sociais, que são fortemente influenciadas pela mediação informacional. Com essa definição, procuramos evidenciar as tenções geradas a partir da disputa pelo controle informacional por parte desses atores. 
Com relação às políticas como mediadoras entre o Estado e os cidadãos, Kerr Pinheiro (2010) as considera como uma cultura coletiva de um grupo ou país, em um instante de sua história. A política deve estabelecer um espaço de negociação onde os diversos grupos sociais possam ser representados.

Para González de Gómez (2002, p. 36), a ação de mediação para comunicação de informações governamentais via artefatos como os portais de transparência, dependerá também de condições como "a convergência dos sistemas e serviços de comunicação e informação pública, a coordenação administrativa de programas e ações de comunicação e informação, bem como a 'articulação' prático-contratual dos sujeitos envolvidos em processos progressivos de democratização".

Na nossa rede conceitual, essa ideia é subsidiada pela abordagem de González de Gómez (2002), que introduz, no debate sobre política de informação, dois conceitos fundamentais para entendermos os dispositivos e artefatos informacionais no contexto das políticas. A autora observa que os sistemas funcionais não possuem uma linguagem comum, e sim linguagens particulares, não havendo comunicação entre os diferentes sistemas. Nesse sentido, nos apresenta as "Micropolíticas inscritas nos dispositivos de informação e as macropolíticas que - direta ou indiretamente - [exprimem] conflitos e interesses em figuras hegemônicas organizadas pelo Estado" (GONZÁLEZ DE GÓMEZ, 2002, p.34).

Estes conceitos são de extrema importância para a análise e formulação de políticas de informação com vistas aos portais de transparência, no contexto da Lei de Acesso à Informação (LAI). Os conceitos mais amplos de política de informação não resolveram os entraves para uma melhor contribuição da Ciência da Informação ao desenvolvimento da cidadania, através da comunicação da informação, por sua deficiência em relação a conceitos mais tecnológicos como usabilidade e acessibilidade. Nesse sentido, o desenvolvimento de micropolíticas de informação torna-se elemento neces- sário para a formulação de políticas de informação mais efetivas, com vistas à utilização dos portais de transparência por seus diversificados usuários na sociedade.

Há a necessidade de uma abordagem sobre as necessidades e habilidades dos usuários e os recursos tecnológicos para atendê-los, que não está merecendo a atenção devida dos formuladores dos portais de transparência, no que diz respeito ao estabelecimento de micropolíticas de informação

\section{CONSIDERAÇÕES FINAIS}

A finalidade do presente relato de pesquisa foi compartilhar nossa visão sobre a accountability e sobre os desafios que as questões da transparência trazem para o campo da Ciência da Informação. Pois accountability é um movimento que acreditamos estar criando raízes na cultura dos brasileiros, e vem se apresentando através dos movimentos sociais, das críticas produtivas, dos questionamentos dos cidadãos e da imposição de sua vontade ao poder público, de modo que podemos dizer que estamos vivenciando um momento de cidadanização nacional.

A convergência de direitos, suas regulamentações e aplicações, além da absorção rápida das tecnologias digitais pela sociedade, nos trouxe a um novo espaço de aprendizagem. Destacamos, aqui, a necessidade de uma concepção do que seja accountability para o campo científico da informação, de modo que os profissionais da informação assumam seu protagonismo nesse movimento e tenham um papel ativo na implantação dos portais de transparência, no contexto da interatividade comunicativa e da ação responsável no trato da coisa pública.

É neste contexto que trabalhamos os portais de transparência governamentais brasileiros, na hipótese de que o conceito de accountability contribui para uma nova e importante fronteira de ação e pesquisa na Ciência da Informação. O desafio está posto. 


\title{
ACCOUNTABILITY: \\ New concept for Information Science?
}

\begin{abstract}
It discusses the changes that have taken place in public management in Brazil in recent decades, arising from the transformations imposed by the 1988 Constitution and the growth of a citizenship movement in the context of the dissemination of digital communication and information technologies. It points out that there is a gap in this discussion in the literature of Information Science and discusses the context of accountability and transparency in Brazil, and information policies in the network society. It emphasizes the need for a conception of what accountability for Information Science is, so that professionals in the field assume the leading role in the citizenship movement for transparency, in the implementation of transparency portals, in the context of communicative interactivity and responsible action in the field of information.
\end{abstract}

Keywords

Public policy. Accountability. Information Science. Information policies. Citizenship. Law of Access to Information. Brazil. Artigo recebido em 22/11/2017 e aceito para publicação em 02/05/2018

\section{REFERÊNCIAS}

ABRUCIO, F. L.; LOUREIRO, M. R. Finanças públicas, democracia e accountability. In: BIDERMAN, C.; ARVATE, P. (Org.). Economia do setor público. $1^{\circ}$ ed. Rio de Janeiro: Elsevier, p. 75-102, 2004.

ASSMANN, H. A metamorfose do aprender na sociedade da informação. Ciência da Informação, Brasília, v.29, n.2, maio/ago., 2000. Disponível em:

$<$ http://www.scielo.br/scielo.php?script=sc i_arttext\&pid=S0100-19652000000200002>. Acesso em 5 maio 2017.

BARRETO, A. A. A questão da informação. São Paulo em Perspectiva, v 8, n 4, p.3-8, out./dez., 1994. Disponível em: http://produtos.seade.gov.br/produtos/spp /v08n04/v08n04_01.pdf.

BRAMAN, S. Defining information policy. Journal of Information Policy, Harrisburg, v. 1, n, 1, p. 1-5, 2011. Disponível em: $<$ http://www.jstor.org/stable/pdf/10.5325 /jinfopoli.1.2011.0001.pdf?refreqid=excelsio r\%3A8d3fa17ddfeca3c4d591535bdb8c575d >.Acesso em: 5 maio 2017.

BRAMAN, S. The emergent global information policy regime. In: The emergent global information policy regime.
Houndsmills, UK: Palgrave Macmillan, 2004. Cap. 2, p. 12-37. Disponível em:

$<$ http://courseweb.ischool.illinois.edu/ kat ewill/spring2011-

$502 / 502 \% 20$ and $\% 20$ other $\% 20$ readings $/$ bra man $\% 202004 \% 20$ emergent $\% 20$ regime.pdf> . Acesso em: 23 maio 2016.

BRASIL. Constituição da República Federativa. Brasília, DF: 1988. Disponível em: $<$ http://www.planalto.gov.br/ccivil_03/con stituicao/constituicaocompilado.htm>. Acesso em: 31 jan. 2015.

BRASIL. Presidência da República. Decreto $\mathbf{n}^{\mathbf{0}} \mathbf{7 . 7 2 4}$, de 16 de maio de 2012. Regulamenta a Lei n. 12.527, de 18 de novembro de 2011, que dispõe sobre o acesso a informações previsto no inciso XXXIII do caput do art. 5o, no inciso II do $\int 3^{\circ}$ do art. 37 e no $\int 2^{\circ}$ do art. 216 da Constituição. Disponível em:

$<$ http://www.planalto.gov.br/ccivil_03/_at o2011--2014/2012/Decreto/D7724.htm>. Acesso em: 31 jan. 2015.

BRASIL. Presidência da República. Lei Complementar, n. 101, 04 de maio de 2000. LRF - Lei de Responsabilidade Fiscal, Brasília, 24 p., maio, 2000. Disponível em: $<$ http://www.planalto.gov.br/ccivil_03/leis /LCP/Lcp101.htm>. Acesso em: 31 jan. 2015. 
BRASIL. Presidência da República. Lei n. 10.683, de 28 de maio de 2003. Dispõe sobre a organização da Presidência da República e dos Ministérios, e dá outras providências, 2003. Disponível em:

$<$ http://www.planalto.gov.br/ccivil_03/leis /2003/L10.683.htm >. Acesso em: 31 jan. 2015.

CAMPOS, A. M. Accountability: quando poderemos traduzi-la para o português? Revista de Administração Pública, Rio de Janeiro, 24 (2), p.30-50, fev./abr. 1990. Disponível em:

$<$ https://accountabilityadmpublica.wikispac es.com/file/view/Accountability-

+ Quando+poderemos+traduzi-

la + par + o+ portugu $\% \mathrm{C} 3 \%$ AAs +-

+ Anna+Maria+Campos.pdf $>$. Acesso em: 25 jan. 2016.

DUARTE, L. F. et al. Vicissitudes e limites da conversão à cidadania nas classes populares brasileiras. Revista Brasileira de Ciências Sociais, São Paulo, vol. 22, n 8, pp.2440, 1993. Disponível em:

$<$ http://www.anpocs.org.br/portal/publica coes/rbcs_00_22/rbcs22_01.htm>. Acesso em: 20 nov. 2016.

FONSECA E SÁ. M. I.; MALIN. A. M. B. Lei de Acesso a Informação: um estudo comparado com outros países. In: XIII Encontro Nacional de Pesquisa em Ciência da Informação. Anais... Rio de Janeiro, out. 2012, Rio de Janeiro: IBICT, 2012.

FREIRE, I. M.; ARAUJO, V. M. R. H. A responsabilidade social da Ciência da Informação. Transiformação, v.11, n. 1, p. 7-15, jan./abr., 1999. Disponível em $:<$ http://periodicos.puc-

campi-

nas.edu.br/seer/index.php/transinfo/article /view/1554/1527. Acesso em: 20 dez. 2014.

FREIRE, I. M. A responsabilidade social da Ciência da Informação e/ou O olhar da consciência possível sobre o campo científico. 2001. 166 f. Tese (Doutorado) IBICT/UFRJ/ECO, Rio de Janeiro, 2001.
Disponível em:

<http://ridi.ibict.br/handle/123456789/34

2>. Acesso em: 15 nov. 2014.

Relato sobre a 'responsabilidade

social na literatura brasileira' da Ciência da

Informação. Pesquisa Brasileira em Ciência da Informação e Biblioteconomia, v.10, n.1, p.212-221, 2015. Disponível em: $<$ http://periodicos.ufpb.br/ojs/index.php/ $\mathrm{pbcib} /$ article/view/24579>. Acesso em: 15 jul. 2015.

FREIRE, I. M.; REGO. H. O. Acesso à informação: os portais de transparência no Brasil. Jornadas Internacionales de Acesso a la Información, Cidade do México, 2016 a.

. Políticas de informação: um olhar sobre os portais de transparência brasileiros. Ciência da Informação em Revista., Maceió, v.3, n.3, p.47-55, set./dez. 2016b.

FREIRE, I. M.; REGO, H. O.; OLIVEIRA, G. M. Os Portais de Transparência à luz da Ciência da Informação: um modelo de interface para acesso à informação. Revista Brasileira em Ciência da Informação e Biblioteconomia. v. 10, n. 1, 2015.

GONZÁLEZ DE GÓMEZ, M. N. Novos cenários políticos para a informação. Ciência da Informação, Brasília, v.31, n.1, p. 27 40, jan./abr. 2002. Disponível em: <http://www.scielo.br/pdf/ci/v31n1/a04v 31n1.pdf>. Acesso em: 10 maio 2016.

Políticas e regimes de informação: perspectivas. In: GARCIA, J. C. R.; TERGINO, M. G. (org.) Desvendando facetas da gestão e políticas de informação. João Pessoa: Editora da UFPB, 2015.

Regime de informação: construção de um conceito. Informação \& sociedade: estudos, João Pessoa, v. 22, n. 3, p.43-60, set./dez. 2012. Disponível em: $<$ Http://www.ies.ufpb.br/ojs/index.php/ie s/article/view/14376/8576>. Acesso em: 03 maio 2016. 
JARDIM, J. M. Lei de acesso a informação pública: dimensões político-informacionais. Tendências da Pesquisa Brasileira em Ciência da Informação, Rio de Janeiro, vol. 5, n. 1. 2012. Disponível em: $<$ http://inseer.ibict.br/ancib/index.php/tp bci/article/viewArticle/68 >Acesso em: 10 fev. 2015.

Políticas públicas de informação: a (não) construção da política nacional de arquivos públicos e privados (1994-2006). In: ENCONTRO NACIONAL DE PESQUISA EM CIÊNCIA DA INFORMAÇÃO, 9, 2008, São Paulo. Anais... São Paulo: USP, 2008. Disponível em:

$<$ http://novo.contagem.mg.gov.br/arquivos $/$ arquivos/infotec/jardim__politicas_publicas_de_informacao.pdf $>$. Acesso em: 10 maio 2016.

KEEN, A. O culto do amador: como blogs, MySpace, You tube e a pirataria digital estão destruindo nossa economia, cultura e valores. Rio de Janeiro: Zahar, 2009.

KERR PINHEIRO, M. M. Estado informacional: implicações para as políticas de informação e de inteligência no limiar do século XXI. Varia História, Belo Horizonte, v.28, n. 47, p. 61-77, jan/jun., 2012. Disponível em:

$<$ http://www.scielo.br/scielo.php?script=sc i_arttext\&pid=S0104-87752012000100004>. Acesso em: 20 abr. 2016.

Processo de transformação das políticas de informação no estado informacional. Pesq. Bras. Ci., Brasília, v.3, n.1, p. 113-126, jan./dez. 2010. Disponível em: $<$ http://inseer.ibict.br/ancib/index.php/tp bci/article/view/30/60 > . Acesso em: 20 abril 2016.

LÉVY, P. A inteligência coletiva: por uma antropologia do ciberespaço. 3. ed. São Paulo: Loyola, 2000.

1999.
MAINWARING, S. Introduction: democratic accountability. in Latin America. In: MAINWARING, S.; WELNA, C. Democratic accountability in Latin America. Oxford. Oxford University Press, New York. p. 3-33, 2003.

MARQUES, R. M, KERR PINHEIRO, M. M. Política de informação nacional e assimetria de informação no setor de telecomunicações brasileiro. Perspectivas em Ciência da Informação, Belo Horizonte, v. 16, n.1, p. 65-91, jan/mar, 2001. Disponível em: <http://www.scielo.br/pdf/pci/v16n1/a05 v16n1.pdf >. Acesso em: 20 abr. 2016.

MEIJER, A. Governmental transparency in historical perspective: from the ancient regime to open data in the Netherlands. International Journal of Public Administration, Los Angeles, v. 38, n. 3, p. 189-199, 2015.

MEIJER, A. Understanding modern transparency. International Review of Administrative Sciences. Los Angeles, V. 75, n. 2, p. 255-269, 2009.

O’DONNELL, G. Accountability horizontal e novas poliarquias. Revista Lua Nova, Cedec, n.44, p. 27-54, 1998. Disponível em: $<$ http://www.scielo.br/pdf/ln/n44/a03n44 .pdf $>$. Acesso em: 18 abr. 2016.

OLIVEIRA, A. G.; CARVALHO, H. A.; CORRÊA, D. P. Governança pública e governabilidade: accountability e disclousure possibilitadas pela contabilidade aplicada no setor público como instrumento de sustentabilidade do Estado. REPeC, Brasília, v.7, n.1, p. 91-104, jan./mar. 2013. Disponível em:

$<$ http://www.repec.org.br/index.php/repec /article/view/256>. Acesso em: 11 nov. 2014.

ORGANIZAÇÃO DAS NAÇÕES UNIDAS (ONU). Internet Rights and Principles Dynamic Coalition. Forum de Governança da Internet das Nações Unidas 
(IRPC). Direitos Humanos Princípios Internet. Nações Unidas, out. 2015.

ORGANIZAÇÃO DAS NAÇÕES UNIDAS PARA A EDUCAÇÃO, A CIÊNCIA E A CULTURA (UNESCO). Information for All Programme (IFAP). Building national information policies: experiences in Latin America. Edited by the Information Society Division, Communication and Information Sector (Editor: Isidro Fernandez-Aballi) - Kingston: UNESCO, 2007 English - Spanish.

PINHO, J. A. G.; SACRAMENTO, A. R. S. Accountability: Já podemos traduzi-la para o português? Revista de Administração Pública. Rio de Janeiro. v. 43, p. 6, p. 1343 1368, nov./dez. 2009. Disponível em:
$<$ http://bibliotecadigital.fgv.br/ojs/index.p $\mathrm{hp} / \mathrm{rap} /$ article/viewFile/6898/5471>. Acesso em: 20 nov. 2015.

SCHEDLER, A. Conceptualizing accountability. In: SCHEDLER, A.; DIAMOND, L.; PLATTNER, M. F. The self-restraining state: power and accountability in new democracies. Boulder and London: Lynner Publishers, p. 23-35, 1999.

ZINS, C. Knowledge map of Information Science. Journal of the American Society for Information Science and Technology, v.58, n.4, p. 526-535, 2007. Disponível em: $<$ http://web.simmons.edu/ weigle/ISEL $\%$ 20ISIC\%20ATTITUDES/zins_kmapof_is.p df >. Acesso em: 11 nov. 2015. 